Sélection de poèmes

Tirés du manuscrit : L'endroit et l'envers

Lise Gaboury-Diallo

novembre 2007

\title{
1. latitudes
}

Vous connaissez les nids de poule? Au Sénégal, on les appelle des nids d'autruches. Vous connaissez les dos d'ânes? Ces reliefs ou bombements transversaux sur la chaussée pour ralentir la circulation?

On leur a donné un autre nom aussi: gendarmes couchés.

Ce n'est pas le seul néologisme qui est né dans cette ville surpeuplée, aux prises avec des politiques improvisées...

je circule dans les rues

encombrées de trous

j'échoue prise au dépourvu

par les dos d'âne et les gendarmes couchés

j'avance dans le secteur viabilisé

rapidement bidonvilisé

je me clochardise

comme toi

ville en proie

à tes fanfaronnades

rurbanisation accélérée

scandaleuses inondations et

débordements désacralisant ces

zones de captage humain réservées

aux pluies d'hivernages troubles

on s'entasse dans les quartiers de la Gueule Tapée

de la Médina des simili-souks dakarois

tapis sous la poussière latéritique

on patauge

dans ces bassins de rétention

réservés à la pluie et à pire

ces surprises en sus

qui couvent toujours

les paysans migrants se logent de travers

dans la gorge d'une péninsule

en goulot d'étranglement

en cette saison la ville rampe

se butant à la pauvreté 
lieu d'équarrissage de dignité à l'ombre du développement abrégé de la FMI et de la Banque mondiale on encaisse encore qui a dit qu'il offrait la part arable ou son équivalent d'ironie avançons là vers le fond même chose de reculons

dansons sur le volcan mais oui et nous les suivons ces assassins des pays non émergeants en voie de sous-développement en avant toujours les copains-coquins 


\section{2. danse}

Les malédictions, les catastrophes, les guerres, les disettes et épidémies ne sont pas les seules réalités qui devraient nous venir à l'esprit lorsqu'on pense à l'Afrique.

Il y a aussi le bonheur et la joie de vivre...

En hommage à ma nièce, bébé Marième, appelée affectueusement Bémarième

elle danse

le sourire en éclats

souffle vital

ses longues jambes trépignent

un rire perlant comme la sueur

les mains en éventail des lames

de ventilateur qui tournent

en rondes de pieds nus

une pulsion de joie frénétique

sans pensée

simplement réduite à l'essentiel

giratoire la terre sous ses orteils

le sable m'éclabousse

elle bat le rythme effréné d'une célébration

entraînante déchaînée ici

dans l'explosion du mouvement 


\section{3. faim}

observons ensemble

le corps assis

très long

démesurément anguleux

les doigts baguettes

poignets d'os d'oiseaux

les coudes pointus de bâtons minces

jusqu'aux articulations d'épaules voûtées

avant l'âge et le dos une tour penchée

retenue par des vertèbres invisibles

étirés aussi comme un filament

longiligne qui aboutit sur un cou gracile

étroit aussi

de la nuque aux hanches puis de l'angle

aux genoux

encore une éternité

l'os du fémur qui n'en finit plus de grandir

qui se prolonge dans le mince jarret

d'adolescent noueux et probablement

pas très tendre

l'accidenté de la faim

qui pousse toujours 